\title{
Composition and Performance of Nanostructured Zirconium Titanium Conversion Coating on Aluminum-Magnesium Alloys
}

\author{
Sheng-xue Yu, ${ }^{1,2}$ Rui-jun Zhang, ${ }^{2}$ Yong-fu Tang, ${ }^{1}$ Yan-ling Ma, ${ }^{1}$ and Wen-chao Du ${ }^{1}$ \\ ${ }^{1}$ Hebei Key Laboratory of Applied Chemistry, College of Environmental and Chemical Engineering, Yanshan University, \\ Qinhuangdao 066004, China \\ ${ }^{2}$ State Key Laboratory of Metastable Materials Science and Technology, Yanshan University, Qinhuangdao 066004, China
}

Correspondence should be addressed to Sheng-xue Yu; yshxue@ysu.edu.cn and Rui-jun Zhang; zhangrj@ysu.edu.cn

Received 13 June 2013; Accepted 11 July 2013

Academic Editor: Xinqing Chen

Copyright (C) 2013 Sheng-xue Yu et al. This is an open access article distributed under the Creative Commons Attribution License, which permits unrestricted use, distribution, and reproduction in any medium, provided the original work is properly cited.

\begin{abstract}
Nanostructured conversion coating of Al-Mg alloy was obtained via the surface treatment with zirconium titanium salt solution at $25^{\circ} \mathrm{C}$ for $10 \mathrm{~min}$. The zirconium titanium salt solution is composed of tannic acid $1.00 \mathrm{~g} \cdot \mathrm{L}^{-1}, \mathrm{~K}_{2} \mathrm{ZrF}_{6} 0.75 \mathrm{~g} \cdot \mathrm{L}^{-1}, \mathrm{NaF} 1.25 \mathrm{~g} \cdot \mathrm{L}^{-1}$, $\mathrm{MgSO}_{4} 1.0 \mathrm{~g} / \mathrm{L}$, and tetra-n-butyl titanate (TBT) $0.08 \mathrm{~g} \cdot \mathrm{L}^{-1}$. X-ray diffraction (XRD), X-ray photoelectron spectroscopy (XPS), and Fourier transform infrared spectrum (FT-IR) were used to characterize the composition and structure of the obtained conversion coating. The morphology of the conversion coating was obtained by atomic force microscopy (AFM) and scanning electron microscopy (SEM). Results exhibit that the zirconium titanium salt conversion coating of Al-Mg alloy contains $\mathrm{Ti}, \mathrm{Zr}, \mathrm{Al}, \mathrm{F}, \mathrm{O}$, $\mathrm{Mg}, \mathrm{C}, \mathrm{Na}$, and so on. The conversion coating with $\mathrm{nm}$ level thickness is smooth, uniform, and compact. Corrosion resistance of conversion coating was evaluated in the $3.5 \mathrm{wt} . \% \mathrm{NaCl}$ electrolyte through polarization curves and electrochemical impedance spectrum (EIS). Self-corrosion current density on the nanostructured conversion coating of Al-Mg alloy is $9.7 \times 10^{-8} \mathrm{~A} \cdot \mathrm{cm}^{-2}$, which is only $2 \%$ of that on the untreated aluminum-magnesium alloy. This result indicates that the corrosion resistance of the conversion coating is improved markedly after chemical conversion treatment.
\end{abstract}

\section{Introduction}

Due to the high strength/weight ratio, easy processing, excellent physical, and chemical properties, aluminum-magnesium-based alloys have been widely used for the materials of automotive, mobile phone, and aircraft $[1,2]$. However low hardness, poor wear resistance, and susceptibility to intergranular corrosion of the aluminum-magnesium alloys hinder their practical application [3]. Under natural conditions, the thin oxide film formed on the surface of aluminum alloy is easily damaged, especially in the acid (alkaline) conditions. The dissolution of this film greatly reduces the corrosion resistance of aluminum and its alloys. Therefore, it is important to improve the corrosion resistance of aluminum alloy through suitable methods. Surface treatment is one of these methods.

Anode oxidation, microarc oxidation, chemical conversion coating, plating, and so on have been widely performed to protect aluminum and aluminum alloys from corrosion [4-7]. Among them, chemical conversion treatment has been attracting more attention due to its facile operation and low cost. Chemical conversion film is formed to oxidize the surface layer into the metal oxide layer [8]. Chromate treatment, including phosphate-chromate method, acid chromate method, and alkaline chromate method, is the concernful treatment method for chemical conversion [912]. Acid chromate treatment is more widely used in the actual application [13]; due to that, the films formed via alkaline chromate treatment are soft, loose, and vulnerable to scratches. Although the passive films have the advantage of simple process, low production cost, and good corrosion resistance, hexavalent chromium is carcinogen which can cause serious harm to humans and environment [14-18]. According to EU scrappage instruction announced on July 1, 2002 , less than $2 \mathrm{~g}$ hexavalent chromium can be used for the production of every car [19]. Simultaneously, the "Restriction 
TABLE 1: Composition of conversion solution.

$\begin{array}{lllll}\text { Tannic acid } & \mathrm{K}_{2} \mathrm{ZrF}_{6}(\mathrm{~g} / \mathrm{L}) & \mathrm{NaF}(\mathrm{g} / \mathrm{L}) & \mathrm{MgSO}_{4}(\mathrm{~g} / \mathrm{L}) & \mathrm{TBT}(\mathrm{g} / \mathrm{L})\end{array}$ $(\mathrm{g} / \mathrm{L})$

\begin{tabular}{lllll}
\hline 1.00 & 0.75 & 1.25 & 1.00 & 0.08
\end{tabular}

of Hazardous Substances" (ROHS) was announced on January 23, 2003 and carried out on July 1, 2006 in EU. According to the instructions, the electrical and electronic products in EU market cannot contain hexavalent chromium and other harmful substances after July 1, 2006 [20]. Therefore, chromefree treatment process has been one of the key technologies for the surface treatment of the aluminum-magnesium alloys. Passivations through molybdate, oxalate, silicate, rare earth metal salt, cerium salt, titanium zirconium salt, phytate system, and silane treatment are widely studied [21-31]. The films formed in these processes are mainly composed of titanium zirconium salts, aluminum oxide, and aluminum fluoride [27]. The advantages of the films formed via these processes are simple operation, good corrosion resistance, and strong combination with the organic polymer [32,33].

In this paper, zirconium and titanium salt were used as the main salt to form zirconium titanium conversion coating on the aluminum-magnesium alloy surface. XRD, SEM, XPS, FT-IR and AFM were applied to characterize the composition, morphology and structure of chemical conversion film coated aluminum-magnesium alloy. Electrochemical measurements were performed to evaluate the corrosion resistance of the chemical conversion film.

\section{Materials and Methods}

Aluminum-magnesium alloys were chosen as the raw materials. A smooth and uniform surface was obtained after pretreatment such as alkaline cleaning, pickling, and activating. For the comparison, all the sizes of samples are $40 \mathrm{~mm} \times 30 \mathrm{~mm} \times 2 \mathrm{~mm}$. The surface process is as follows: sample $\rightarrow$ polishing $\rightarrow$ removing oil $\rightarrow$ alkaline cleaning $\rightarrow$ pickling $\rightarrow$ rinsing $\rightarrow$ chemical conversion treatment $\rightarrow$ rinsing $\rightarrow$ drying. The composition of conversion solution is shown in Table 1.

$\mathrm{X}$-ray diffraction (XRD) was carried out to characterize crystalline structure and composition of the conversion coating. X-ray photoelectron spectroscopy (XPS) was performed to examine the surface composition and element valence state of conversion coating. Meanwhile, Fourier transform infrared absorption spectra (FT-IR) were picked to identify compound structure of titanium salt conversion coating. SEM and AFM were selected to analyze the surface morphology of zirconium titanium conversion coating.

CHI660A electrochemical workstation (CH Instrument Corp., Shanghai, China) was used to conduct polarization test. The corrosion test was carried out in $3.5 \mathrm{wt} . \% \mathrm{NaCl}$ solution at $25^{\circ} \mathrm{C}$ with standard three-electrode system. Sample, saturated calomel electrode (SCE), and platinum sheet were used as working electrode, reference electrode, and auxiliary electrode, respectively.

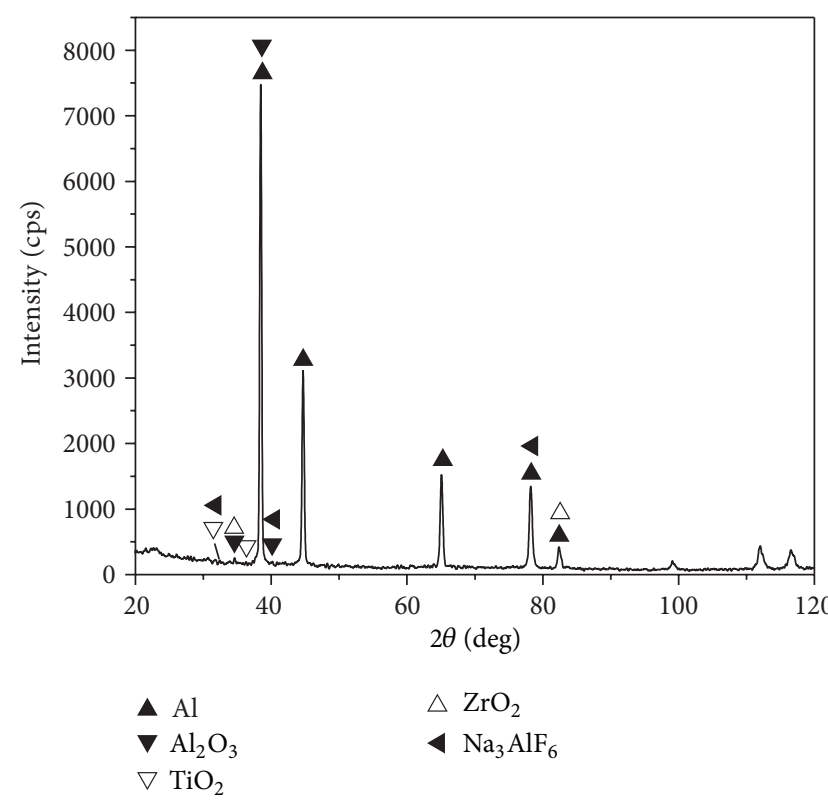

FIGURE 1: Zirconium titanium salt conversion coating of XRD analysis.

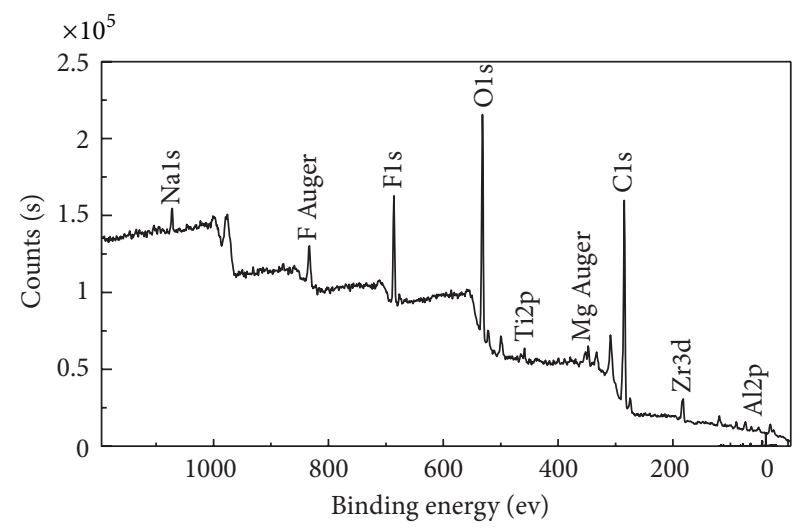

FIGURE 2: XPS of titanium zirconium salt conversion coating.

\section{Results and Discussion}

3.1. XRD Analysis. XRD is used to analyze the composition of zirconium titanium salt conversion coating. As shown in Figure 1, the film layer obviously contains large amounts of aluminum due to that aluminum is the substrate. Diffraction peaks attributed to $\mathrm{ZrO}_{2}, \mathrm{TiO}_{2}, \mathrm{Al}_{2} \mathrm{O}_{3}$ and $\mathrm{Na}_{3} \mathrm{AlF}_{6}$ phases are also observed. These substances are generated from the surface conversion of aluminum-magnesium alloy substrate. Because the conversion coating is thinner, powder scraping from aluminum-magnesium alloy contains less conversion coating. As observed, diffraction peaks of the aluminum alloy substrate are very strong, while the diffraction peaks of other phases are very weak. Therefore, it is proposed that some materials in the conversion coating have not been detected.

3.2. XPS Analysis. Figure 2 shows the XPS of zirconium titanium salts conversion coatings on the $\mathrm{Al}-\mathrm{Mg}$ alloy. $\mathrm{Ti}$, 


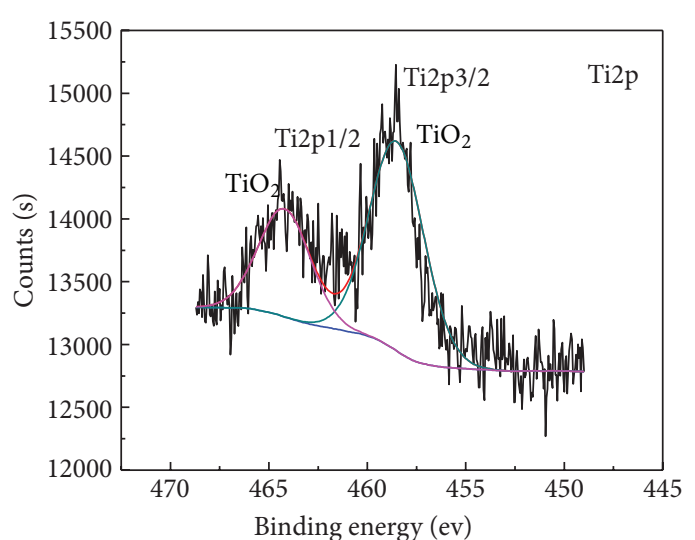

(a)

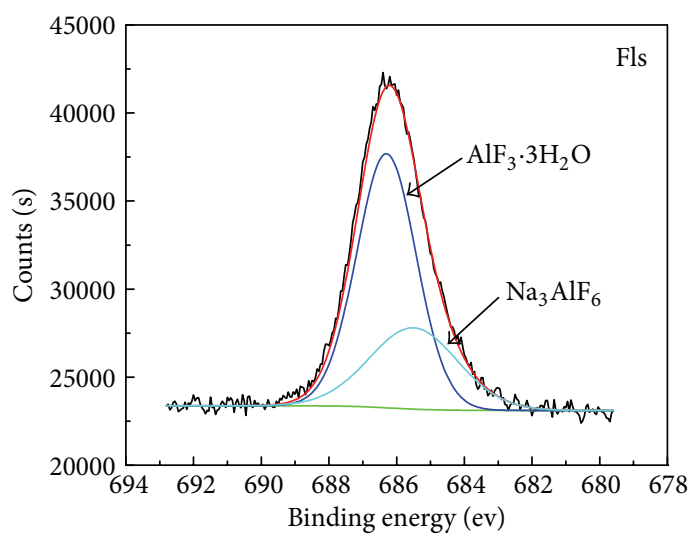

(c)

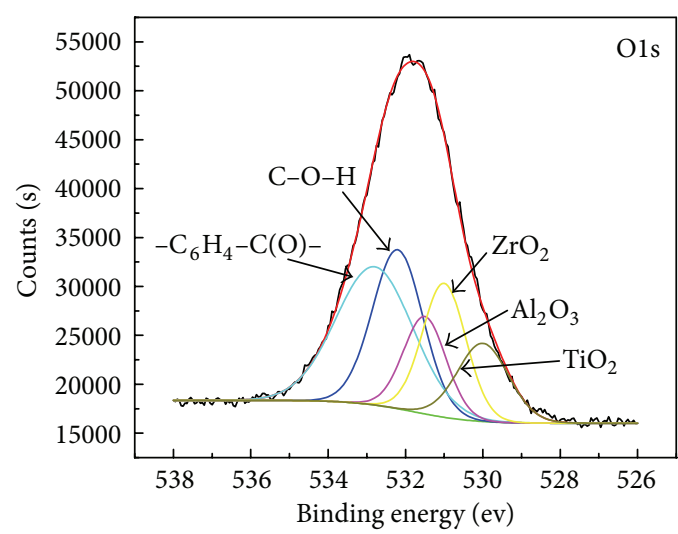

(e)

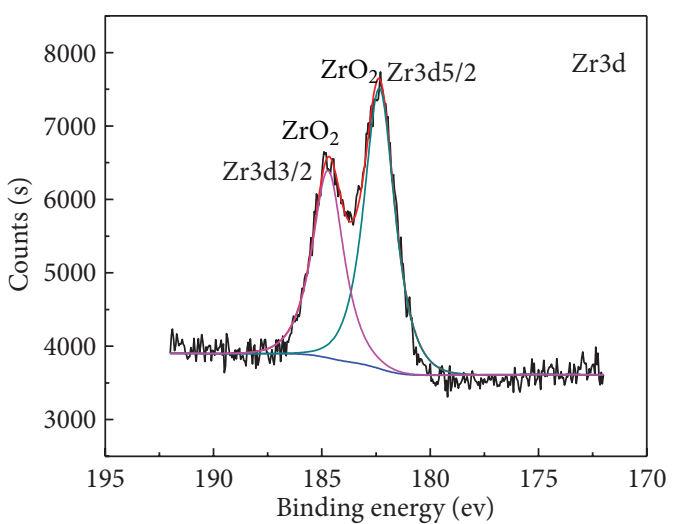

(b)

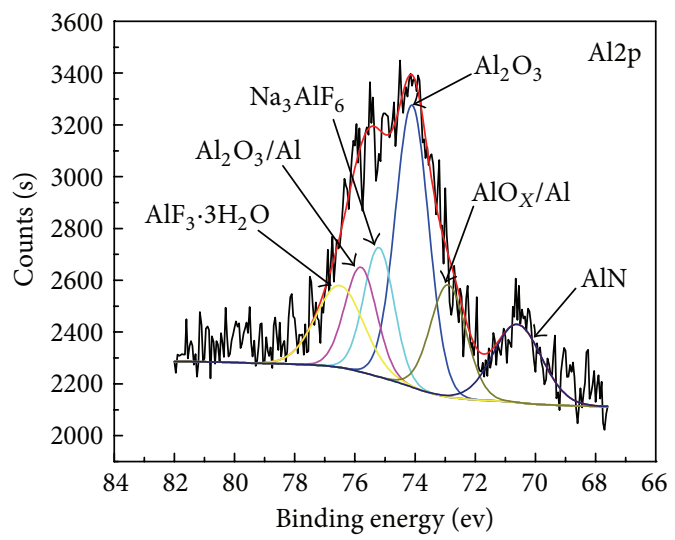

(d)

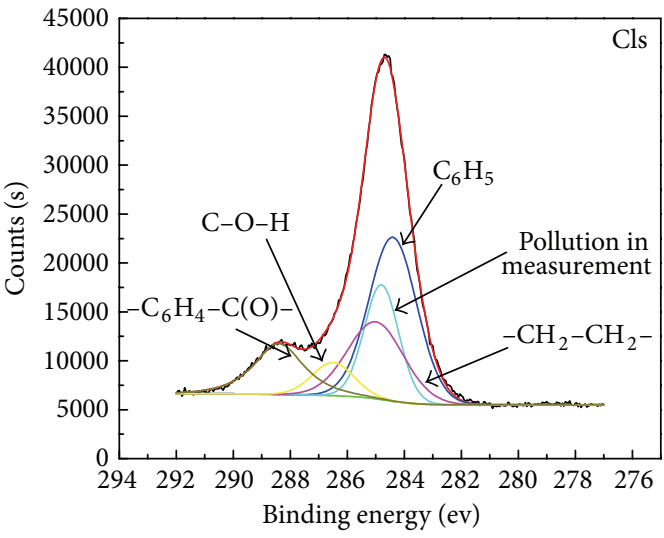

(f)

FIGURE 3: XPS of narrow area scan spectra of the elements conversion coating of titanium zirconium salt: (a) Ti2p, (b) Zr3d, (c) F1s, (d) Al2p, (e) O1s, and (f) Cls.

$\mathrm{Zr}, \mathrm{Al}, \mathrm{F}, \mathrm{O}, \mathrm{C}, \mathrm{Na}, \mathrm{Mg}$, and other elements were contained in zirconium titanium salt conversion coating. Most of the elements in the solution are observed in the conversion coating. This result indicates that the conversion coating is derived from the cooperation of all the compositions of the conversion solution. The $\mathrm{H}$ element cannot be detected by XPS. Therefore, it cannot rule out the existence of $\mathrm{H}$.

Figure 3 is the narrow area scan spectra of Ti2p, Zr3d, $\mathrm{Al} 2 \mathrm{p}, \mathrm{F} 1 \mathrm{~s}, \mathrm{O} 1 \mathrm{~s}$, and C1s. Spectra peaks of each element were fitted and analyzed according to XPS database, established by the national standard technology association (NIST X-ray Photoelectron Spectroscopy Database), through XPS Peak 4.1 software.

Ti2p spectrum (Figure 3(a)) is composed of two fitted peaks at $458.66 \mathrm{eV}$ and $464.41 \mathrm{eV}$, corresponding to the $\mathrm{Ti} 2 \mathrm{p} 3 / 2$ and $\mathrm{Ti} 2 \mathrm{p} 1 / 2$ of $\mathrm{TiO}_{2}$ from XPS database, respectively. These results indicate that $\mathrm{Ti}$ exists as the $\mathrm{TiO}_{2}$ state. 


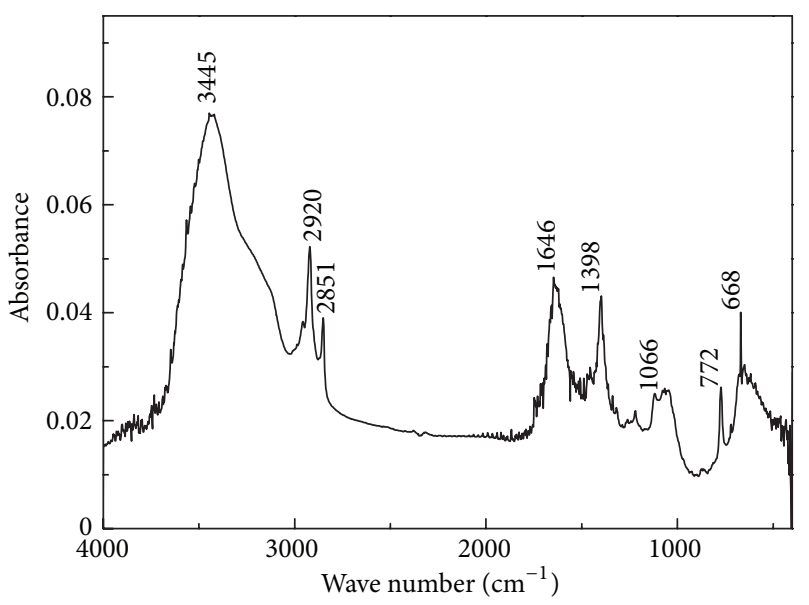

(a)

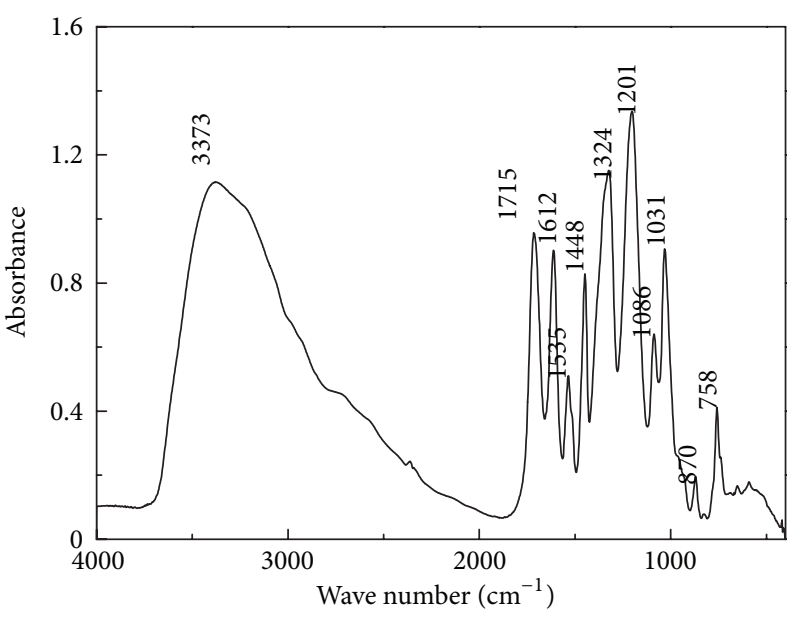

(b)

FIGURE 4: Fourier transform infrared spectrum of zirconium titanium salt conversion coating and tannic acid: (a) zirconium titanium salt conversion coating, (b) the tannic acid.

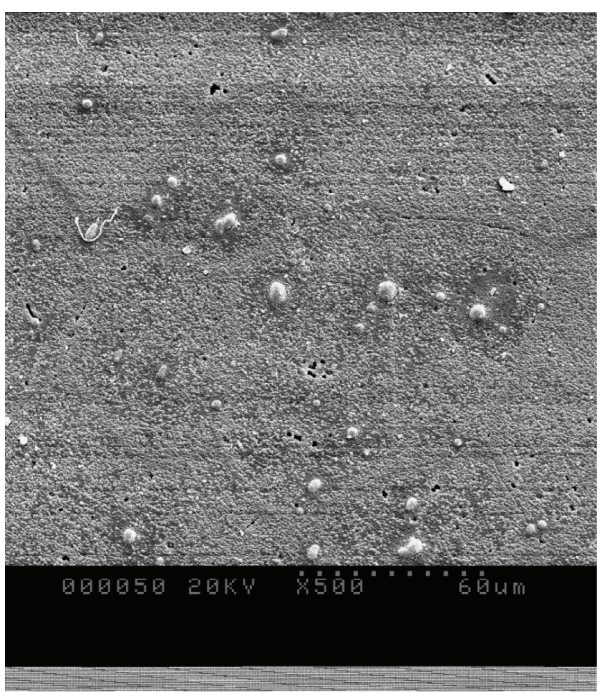

(a)

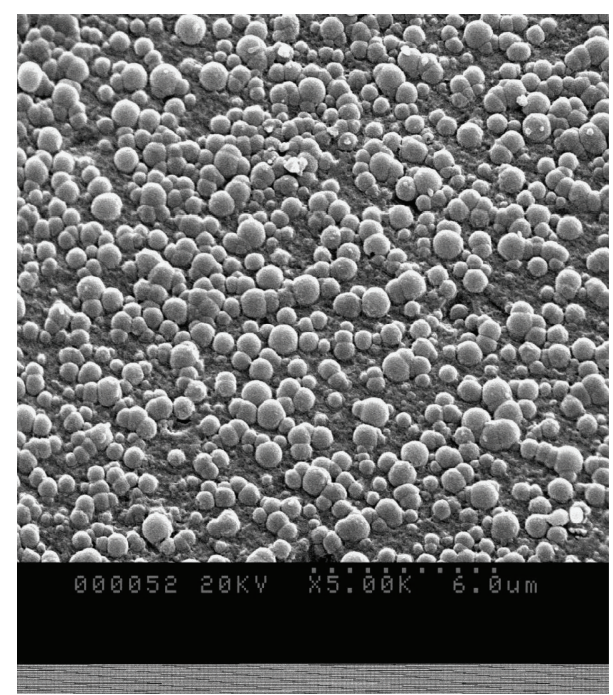

(b)

FIGURE 5: SEM morphology of aluminum zirconium titanium conversion coating: (a) $\times 500$, (b) $\times 5.00 \mathrm{k}$.

Zr3d spectrum (Figure 3(b)) is composed of two fitted peaks at $182.45 \mathrm{eV}$ and $184.70 \mathrm{eV}$. The two peaks are attributed to $\mathrm{Zr} 2 \mathrm{~d} 5 / 2$ and $\mathrm{Zr} 3 \mathrm{~d} 3 / 2$ of $\mathrm{ZrO}_{2}$, indicating that $\mathrm{Zr}$ exists as combination state of $\mathrm{ZrO}_{2}$.

Figure 3(c) shows $\mathrm{F}$ elements in conversion coating surface. It mainly exists in the form of $\mathrm{AlF}_{3} \cdot 3 \mathrm{H}_{2} \mathrm{O}$ and $\mathrm{Na}_{3} \mathrm{AlF}_{6}$ compounds. As seen in Figure 3(d), Al element in conversion coating is mainly based on $\mathrm{AlN}, \mathrm{Al}_{2} \mathrm{O}_{3} / \mathrm{Al}, \mathrm{Al}_{2} \mathrm{O}_{3}, \mathrm{AlO}_{x} / \mathrm{Al}$, $\mathrm{AlF}_{3} \cdot 3 \mathrm{H}_{2} \mathrm{O}$, and $\mathrm{Na}_{3} \mathrm{AlF}_{6}$ compound form. The peaks of $\mathrm{C}$ and $\mathrm{O}$ can be attributed to organic functional groups (Figures $3(\mathrm{e})$ and 3(f)), revealing that the $\mathrm{C}$ and $\mathrm{O}$ mainly exist as complex compound.

To sum up, $\mathrm{Zr}$ and $\mathrm{Ti}$ elements in the conversion film exist as $\mathrm{Ti}^{4+}$ and $\mathrm{Zr}^{4+}$, respectively. Al element mainly exists as oxides and complexes, and $\mathrm{C}$ element may be in the form of organic polymers.
3.3. FT-IR Analysis. Figure 4 is the Fourier transform infrared spectrum of zirconium titanium salt conversion coating and tannic acid, respectively. The peak located at $3445 \mathrm{~cm}^{-1}$ can be assigned to hydroxy benzoic acid. Compared to the benzoic hydroxy of tannic acid $\left(3375 \mathrm{~cm}^{-1}\right)$, the higher wave number shift $\left(3445 \mathrm{~cm}^{-1}\right)$ can be attributed to the lower complexation extent of benzoic hydroxyl. The peaks at $2920 \mathrm{~cm}^{-1}$ and $2851 \mathrm{~cm}^{-1}$ should be attributed to the symmetric and asymmetric vibration of the methylene, respectively, indicating the transformation reaction of tetran-butyl titanate in the process of conversion coating. The characteristic peak at $1715 \mathrm{~cm}^{-1}$ can be ascribed to the ketonic group of tannic acid, which shifts to $1646 \mathrm{~cm}^{-1}$ after chemical conversion. The shift is corresponding to the hydrolyzation of tannic acid. The peaks at $1600 \sim 1450 \mathrm{~cm}^{-1}$ and $1250 \sim 700 \mathrm{~cm}^{-1}$ 


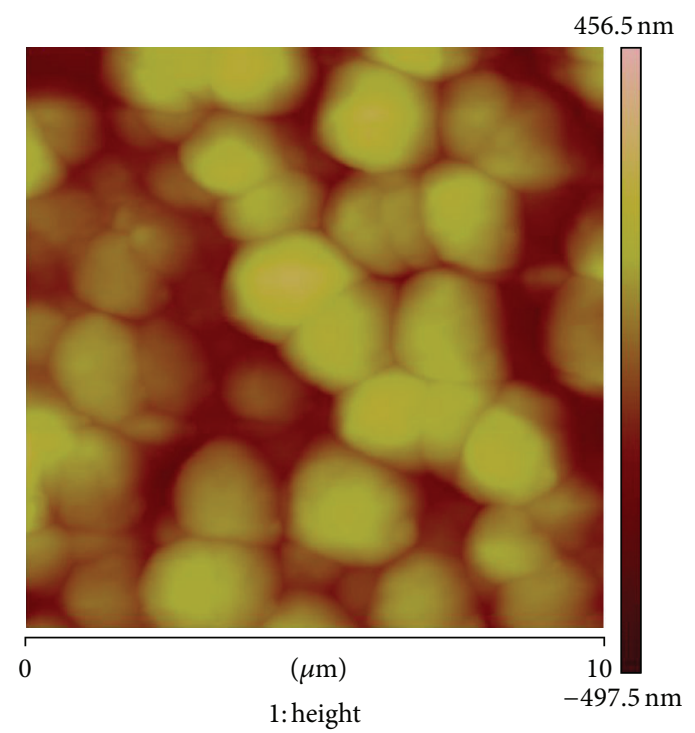

(a)

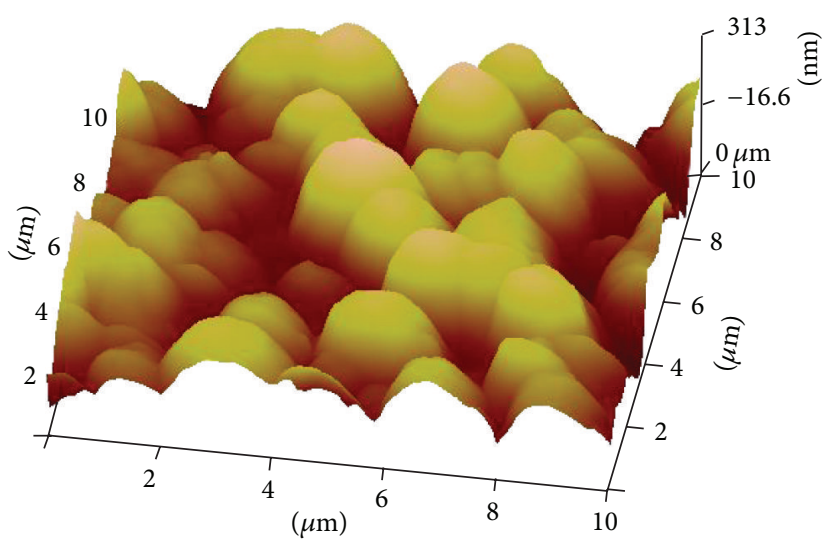

(b)

FIgURE 6: AFM images of zirconium titanium salt conversion coating $(10 \mu \mathrm{m} \times 10 \mu \mathrm{m})$.

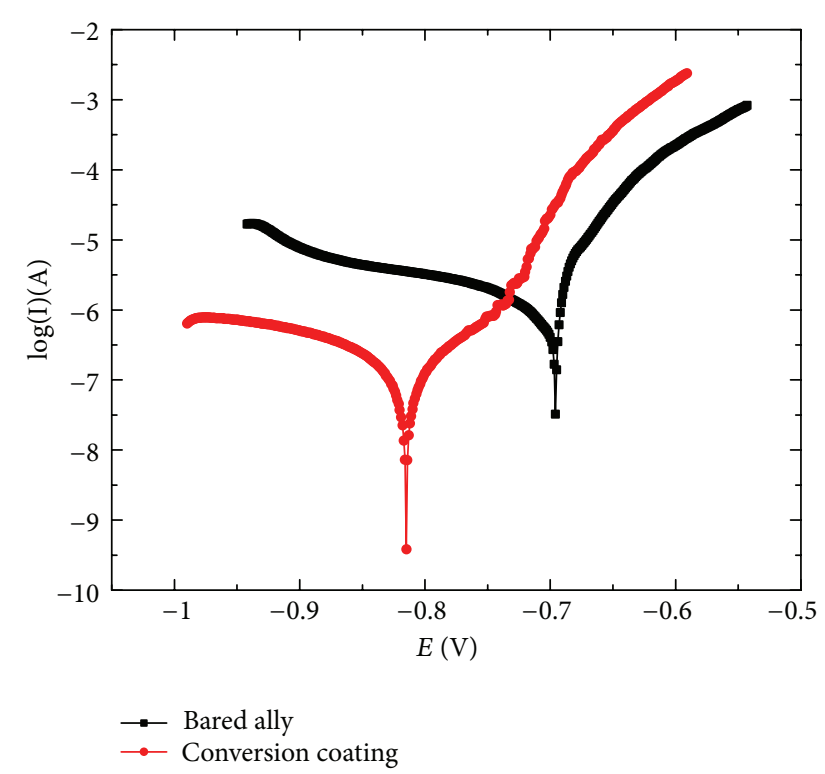

FIGURE 7: Aluminum-magnesium alloy polarization curves before and after conversion treatment.

of conversion coating are attributed to the characteristic adsorption of benzoic group, which are clearly different with that of Tannic acid. The changes of benzoic groups are mainly due to two reasons: the change of the benzoic groups' number and the reaction of benzoic group with other groups. In this study, the change is ascribed to the complexation between the metal ion and the trihydroxy-benzoic acid derived from hydrolyzation of tannic acid.

From the previous analysis, we can conclude that the metals on the surface transform to metal compounds after conversion treatment. Hydroxide, ketonic, and benzoic groups are formed on the surface of the aluminum-magnesium alloy. These groups will be propitious to improve the contact between the substrate and the oil paint for the consequent coating.

3.4. SEM Analysis. Figure 5 shows the SEM images of the conversion coating at various magnifications. The conversion coating film layer is uniform, smooth, dense, continuous, no damage, and cracking behavior. Almost no defects in the zirconium titanium salt conversion coating are observed. The particles are homogeneous spherical grains.

3.5. AFM Analysis. The three-dimensional morphology of the film was observed by atomic force microscope (AFM). Figure 6 is the images with the scanning area of $5 \mu \mathrm{m} \times$ $5 \mu \mathrm{m}$, respectively. As shown, the conversion coating surface is smooth and uniform. The size of the surface particle is narrowly distributed. The part of graph with bright color represents the region with high level position, while the part with dim color is the lower level position. For analysis, the height difference is less than $50 \mathrm{~nm}$, which indicates that the thickness of the conversion film is nanoscale.

3.6. Polarization Curve Analysis. Tafel polarization curves of aluminum-magnesium alloy before and after conversion process, performed in $3.5 \% \mathrm{NaCl}$ solution, are shown in Figure 7. Electrochemical parameter calculated by polarization curve can be seen in Table 2. The corrosion current density of the blank sample and zirconium titanium conversion coating is $4.701 \times 10^{-6} \mathrm{~A} \cdot \mathrm{cm}^{-2}$ and $9.7 \times 10^{-8} \mathrm{~A} \cdot \mathrm{cm}^{-2}$, respectively. The corrosion current density of conversion coating is reduced by two orders of magnitude, about $2 \%$ of that on the blank sample.

3.7. EIS Analysis. The Ac impedance spectroscopy of the aluminum-magnesium alloy (Figure 8(a)) before and after 


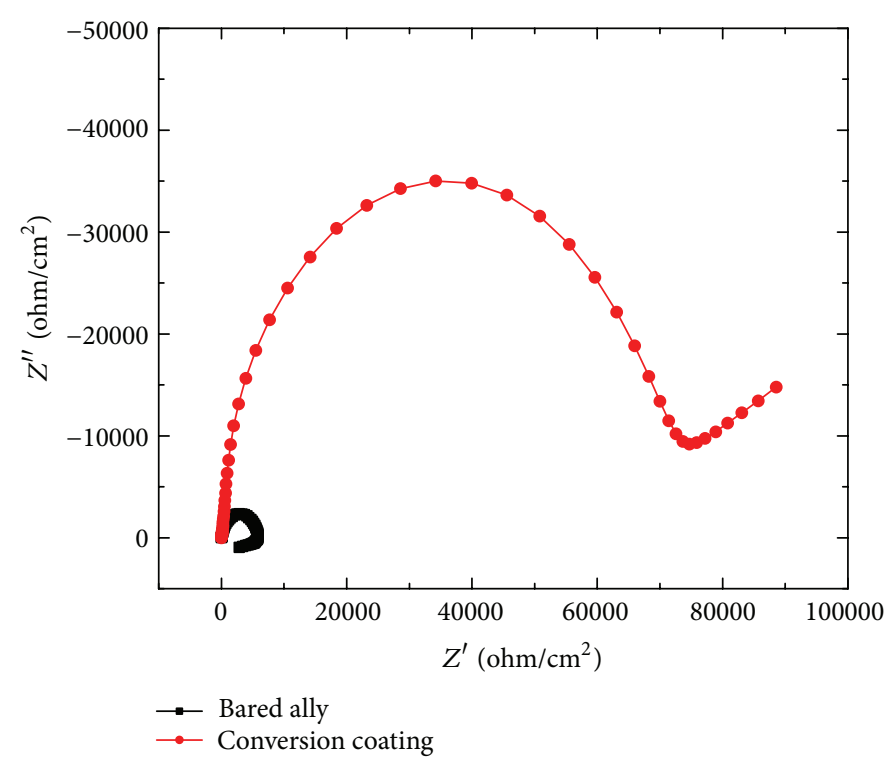

(a)

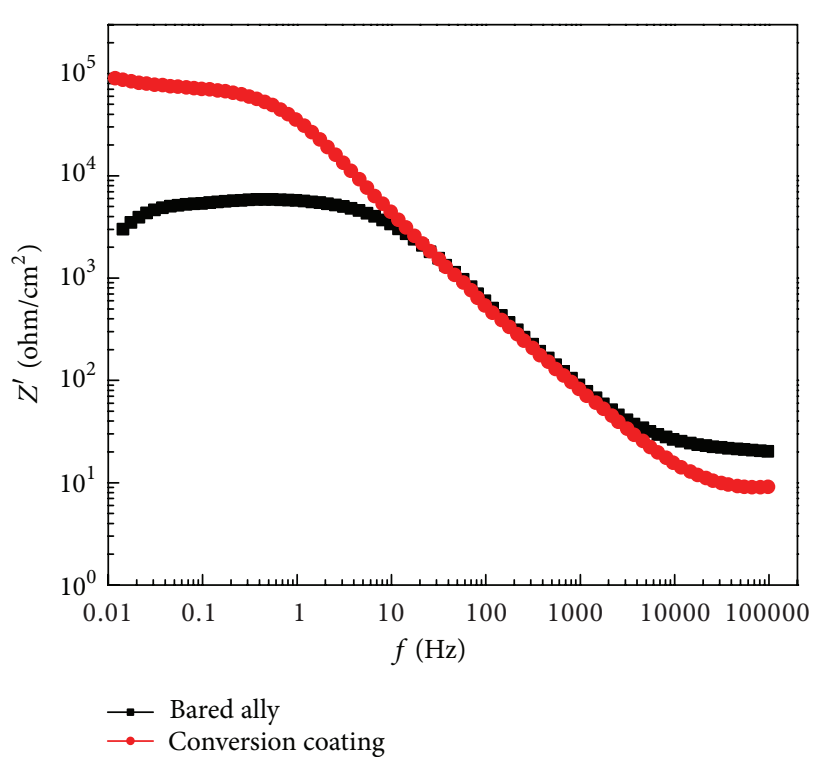

(b)

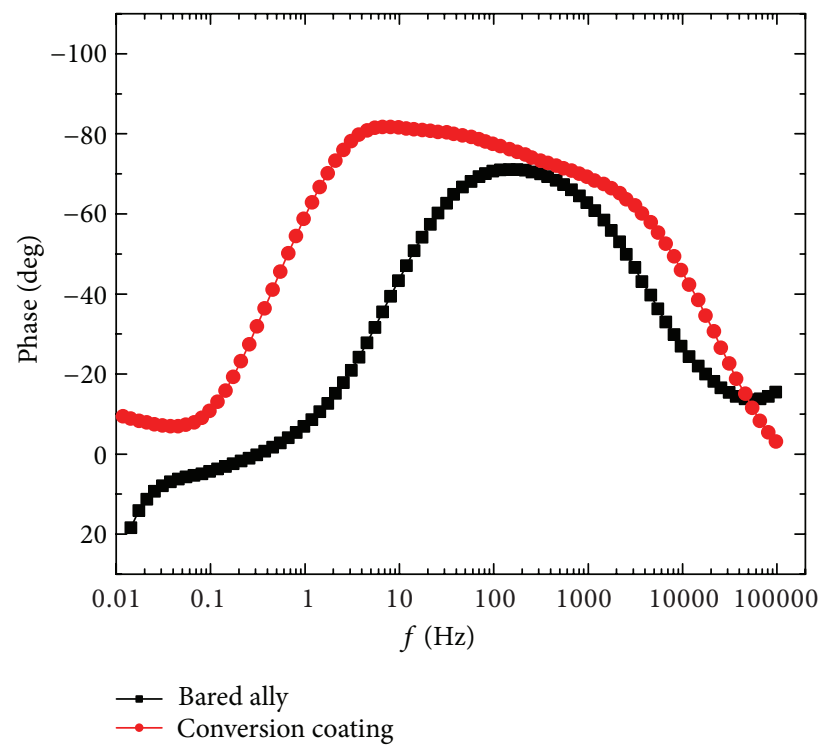

(c)

FIGURE 8: Aluminum-magnesium alloy AC impedance curves before and after treatment: (a) Nyquist diagram; (b) impedance Bode diagram; (c) the phase angle Bode diagram.

TABLE 2: Electrochemical parameters.

\begin{tabular}{lcccc}
\hline The sample & $E_{\text {corr }}$ & $E_{\text {pit }}$ & $\Delta E$ & $i_{\text {corr }}$ \\
& $\mathrm{V}$ & $\mathrm{V}$ & $\mathrm{V}$ & $\mathrm{A} / \mathrm{cm}^{2}$ \\
\hline Blank sample & -0.697 & -0.697 & 0 & $4.701 \times 10^{-6}$ \\
Conversion coating & -0.815 & -0.730 & 0.085 & $9.7 \times 10^{-8}$ \\
\hline
\end{tabular}

conversion process is very different. The Ac impedance spectroscopy of untreated aluminum-magnesium alloy is composed of high frequency capacitive impedance arc and low frequency inductive impedance arc. However, the low frequency inductive impedance arc is not observed in the Ac impedance spectroscopy of the aluminum-magnesium alloy after being treated. The resistance and capacitive impedance of the film can be investigated through comparing the diameter of the high frequency capacitive reactance arc. As shown, the resistance and capacitive impedance of aluminum-magnesium alloy specimen after chemical conversion processing is greater than that of aluminum-magnesium alloy specimen without the conversion process. It indicates that polarization resistance is increasing when the corrosion reaction occurred. Conversion coating can effectively slow down the electron transfer within the coating layer and protect aluminum-magnesium alloy matrix from erosion caused by the corrosive medium. These effects will improve the corrosion resistance of aluminum-magnesium alloy. 
Inductive impedance arc in the low frequency, corresponding to the dissolution of conversion coating on the surface of aluminum-magnesium alloy (mainly alumina) in corrosive $\mathrm{Cl}^{-}$medium, is observed in the EIS spectroscopy of aluminum magnesium alloy without conversion process. The rate of dissolution increases continuously, leading to conversion film being thinner, and then causes holey corrosion. On the contrary, inductive reactance arc in the low frequency is absent in the EIS spectroscopy of aluminummagnesium alloy through transformation processing. This is due to the fact that conversion coating on the surface of the aluminum-magnesium alloy effectively inhibits dissolving penetration of corrosive medium into conversion coating. Aluminum-magnesium alloy conversion coating greatly improves the corrosion resistance of aluminum-magnesium alloy and effectively protects the alloy matrix.

Figures $8(\mathrm{~b})$ and $8(\mathrm{c})$ are the Bode diagram and phase angle Bode diagram of the AC impedance spectroscopy of aluminum-magnesium alloy before and after the conversion process. The impedance of the aluminum-magnesium alloy after conversion is an order of magnitude greater than that without the conversion process. It implies that aluminum-magnesium alloy after conversion treatment has better corrosion resistance. The phase angle Bode diagram of untreated aluminum-magnesium alloy has a time constant at the phase angle of 70 degree. Meanwhile, aluminum-magnesium alloy after conversion treatment displays a time-constant value around 85 degrees at the frequency of $1-10 \mathrm{~Hz}$. These results imply that the conversion coating is uniform.

\section{Conclusions}

Uniform, continuous Ti-Zr conversion coating can be successfully prepared using $\mathrm{NaF}, \mathrm{TBT}, \mathrm{K}_{2} \mathrm{ZrF}_{6}$, Tannic acid, and $\mathrm{MgSO}_{4}$ as film-forming substances under the condition of $25^{\circ} \mathrm{C}$.

Electrochemical tests show that corrosion current density of conversion coating on titanium zirconium conversion coating is $9.7 \times 10^{-8} \mathrm{~A} \cdot \mathrm{cm}^{-2}$, which is only about $2 \%$ of that of the aluminum-magnesium alloy substrate. Impedance value of the conversion coating is about an order of magnitude larger than that of the untreated aluminum-magnesium alloy. Therefore, the corrosion resistance of aluminum-magnesium alloy is significantly enhanced after surface conversion coating.

AFM and SEM results exhibited that the dense and uniform $\mathrm{Ti}-\mathrm{Zr}$ conversion coating is made of small spherical particles with uniform size and contains $\mathrm{Ti}, \mathrm{Zr}, \mathrm{Al}, \mathrm{Mg}, \mathrm{OH}$, and so on.

\section{Acknowledgment}

This project was financially supported by the Science \& Technology Development Program of Qinhuangdao City of Hebei Province of China (Grant no. 2010011A098).

\section{References}

[1] M. Okido, R. Ichino, S.-J. Kim, and S.-K. Jang, "Surface characteristics of chemical conversion coating for $\mathrm{Mg}-\mathrm{Al}$ alloy," Transactions of Nonferrous Metals Society of China, vol. 19, no. 4, pp. 892-897, 2009.

[2] Y. Kuang, Y. Xu, and G. Li, "Research advances on the surface treatment of aluminum magnesium alloy and its alloy," Plating and Finishing, vol. 22, no. 1, pp. 16-20, 2000.

[3] M. Wu and Y. Sun, "Development of surface treatment for aluminum magnesium alloy and its alloys," Surface Technology, vol. 32, no. 3, pp. 13-15, 2003.

[4] J. Zhang, C. Li, and G. Cao, "Corrosion resistance of anodically oxidized LY12 aluminum magnesium alloy alloy after modification with cerium nitrate and silane," Electroplating \& Finishing, vol. 29, no. 12, pp. 33-37, 2010.

[5] B. Liu, M. Yi, X. Xiong et al., "Manufacture and corrosionresistance of chemical conversion film of cast aluminium 104 alloy," Surface Technology, vol. 29, no. 5, pp. 17-18, 2000.

[6] J. Li and N. Li, "A study of black nickel electroplating on AC aluminum magnesium alloy alloy anodic oxide coating," Electroplating \& Pollution Control, vol. 30, no. 2, pp. 37-40, 2010.

[7] J. Yang, Y. Li, Y. Ma et al., "Effects of $\mathrm{NaOH}$ on micro-arc oxidation coating and its corrosion resistance of A356 alloy," China Surface Engineering, vol. 21, no. 5, pp. 49-53, 2008.

[8] W. Zhang, "Discussion on the surface treatment and the conduction protecting technique for the surface of the aluminum magnesium alloy and its alloy," Electronics Process Technology, vol. 26, no. 6, pp. 357-359, 2005.

[9] D. Chen, Z. Huang, and W. Li, "Study of chrome-free chemical conversion film on aluminium alloy," Surface Technology, vol. 26, no. 12, pp. 38-39, 2005.

[10] A. E. Hughes, R. J. Taylor, and B. R. W. Hinton, "Chromate conversion coatings on $2024 \mathrm{Al}$ alloy," Surface and Interface Analysis, vol. 25, no. 4, pp. 223-234, 1997.

[11] Q. Meng and G. S. Frankel, "Characterization of chromate conversion coating on AA7075-T6 aluminum alloy," Surface and Interface Analysis, vol. 36, no. 1, pp. 30-42, 2004.

[12] N. Le Bozec, S. Joiret, D. Thierry, and D. Persson, "The role of chromate conversion coating in the filiform corrosion of coated aluminum alloys," Journal of the Electrochemical Society, vol. 150, no. 12, pp. B561-B566, 2003.

[13] W. Wang, "Conversion coatings treatment for $\mathrm{Al}$ and its alloys," Electropating \& Pollution Control, vol. 22, no. 6, pp. 24-25, 2002.

[14] X. Xiao, L. Xu, C. Deng et al., "Chromium-free fluorozirconatebased chemical conversion coatings on aluminum magnesium alloy and aluminum magnesium alloy alloys," Electroplating \& Finishing, vol. 30, no. 10, pp. 37-40, 2011.

[15] A.-H. Yi, W.-F. Li, J. Du, S.-L. Mu, and N.-H. Liu, "Formation mechanism and properties of colored $\mathrm{Ti} / \mathrm{Zr}$-based conversion coating on aluminum alloy," Journal of South China University of Technology (Natural Science), vol. 40, no. 1, pp. 101-124, 2012.

[16] H. Li, Z. Meng, Y. Han et al., "Study on the corrosion resistance of chromium-free phosphate rare earth conversion coating on 6061 aluminum alloy," Paint \& Coatings Industry, vol. 42, no. 8, pp. 69-72, 2012.

[17] L. Xu, R. Guo, C. Tang et al., "Study on a golden-yellow conversion coating on aluminum alloy," Surface Technology, vol. 40, no. 1, pp. 78-80, 2011. 
[18] H. Yu, A. Yuan, D. Wei, X. Tan, and Y. Han, "Preparation and electrochemical characteristics of trivalent chromiumzirconium hybrid coatings on 6063 aluminum alloy," CIESC Journal, vol. 62, no. 10, pp. 2861-2866, 2011.

[19] W. John and B. Ibber, "Chromate-free conversion coatings for aluminum magnesium alloy," in Proceedings of the AESF Annual Technical Conference, pp. 425-433, 2002.

[20] R. Guo, J. Yang, and J. Kang, "Titanate-based conversion coatings on aluminum magnesium alloy alloys," Electroplating \& Finishing, vol. 25, no. 1, pp. 46-48, 2006.

[21] C. Wang, F. Jiang, and H. Lin, "The molybdate conversion coatings on LY12 aluminum alloy," Rare Metal Materials and Engineering, vol. 32, no. 2, pp. 130-133, 2003.

[22] X. Fang, R. Guo, L. Zhang et al., "Novel fluorosilicate conversion process on aluminum magnesium alloy alloys," Electroplating \& Finishing, vol. 31, no. 5, pp. 37-40, 2012.

[23] D.-C. Chen, W.-F. Li, W.-H. Gong, G.-X. Wu, M.-S. Huang, and Y.-Q. Liang, "Preparation of chrome-free chemical conversion coating on aluminum alloy and its performance," The Chinese Journal of Nonferrous Metals, vol. 18, no. 10, pp. 1839-1845, 2008.

[24] J. Zhang, C. Yang, L. Pan, and C. Li, "Electrochemical study of corrosion resistance of cerium nitrate doped silane-based hybrid films on aluminum alloy 2A12," Acta Metallurgica Sinica, vol. 44, no. 11, pp. 1372-1377, 2008.

[25] J. Wang, J. Wu, and G. Chen, "The technique of rare-earth conversion coatings on aluminum alloy," Electrochemistry, vol. 9, no. 3, pp. 350-355, 2003.

[26] M. Vippola, S. Ahmaniemi, J. Keränen et al., "Aluminum phosphate sealed alumina coating: characterization of microstructure," Materials Science and Engineering A, vol. 323, no. 1-2, pp. $1-8,2002$.

[27] Z. Xiong, L. Gu, X. Liu, Y. Wang, Y. Li, and Z. Wang, "Research development on substitutive processes for chromate conversion coatings concerning aluminum alloy," Guangzhou Chemical Industry, vol. 40, no. 19, pp. 14-16, 2012.

[28] J.-M. Long, Z.-C. Guo, X.-Y. Han, and N. Yang, "Study of a new chromium-free conversion coating formed on $\mathrm{ZnAl}$ alloy," Transactions of Materials and Heat Treatment, vol. 25, no. 5, pp. 1149-1153, 2004.

[29] M. Qi, C. Guan, and M. Ru, "Preparation and corrosion resistance of phytate conversion coating," Materials Protection, vol. 45, no. 1, pp. 1-3, 2012.

[30] Y. Jiang, H. Zhou, and S. Zeng, "Performance of oxalate chemical conversion coating on magnesium alloy," Materials Protection, vol. 42, no. 9, pp. 10-15, 2009.

[31] Y. Lv, J. Xiong, L. Chen et al., "Process of chrome-free chemical conversion film on aluminum alloys," Electroplating \& Finishing, vol. 26, no. 12, pp. 25-28, 2007.

[32] N. Liu, W. Li, and J. Du, "Study on the structure and corrosion resistance of chromatic Ti-Zr based conversion layer on 6063 aluminum magnesium alloy," Surface Technology, vol. 39, no. 5, pp. $45-47,2010$.

[33] X. Jin and J. D. Scantlebury, "An investigation of paint adhesion to chromate conversion coating on aluminum alloys," Materials Protection, vol. 25, no. 4, pp. 4-9, 1992. 

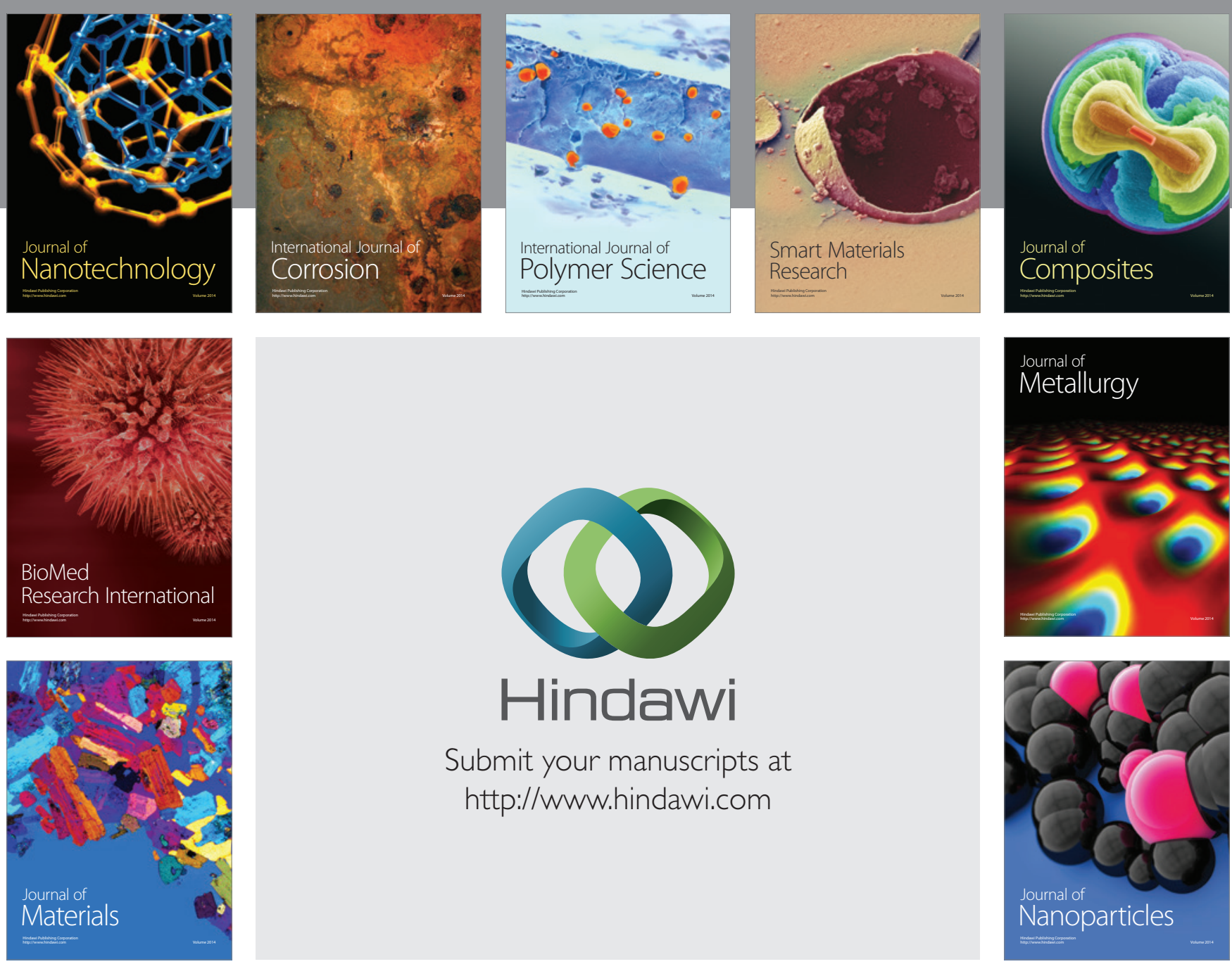

Submit your manuscripts at http://www.hindawi.com
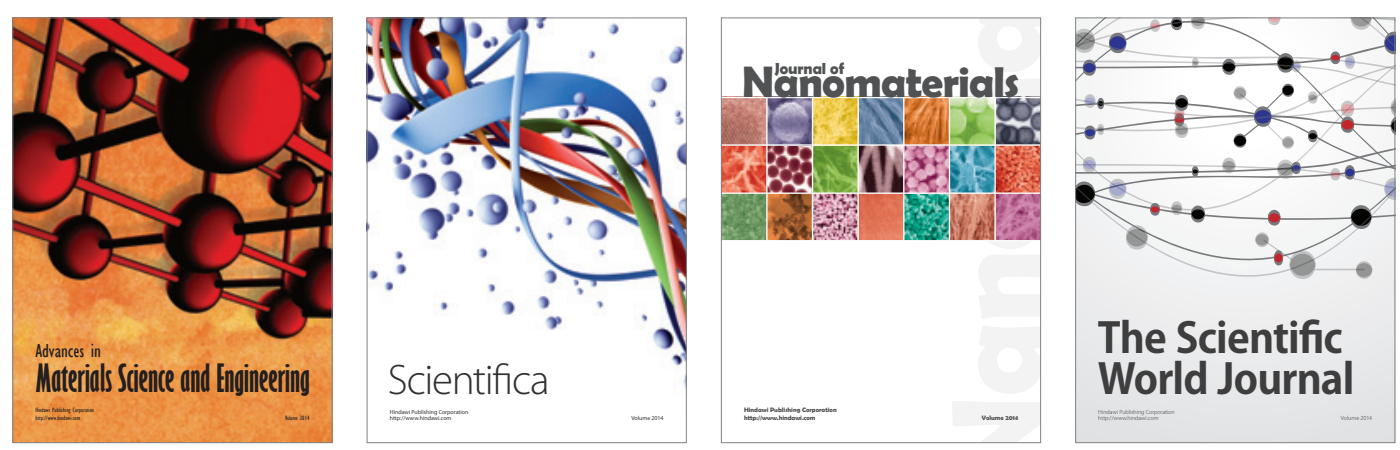

\section{The Scientific World Journal}
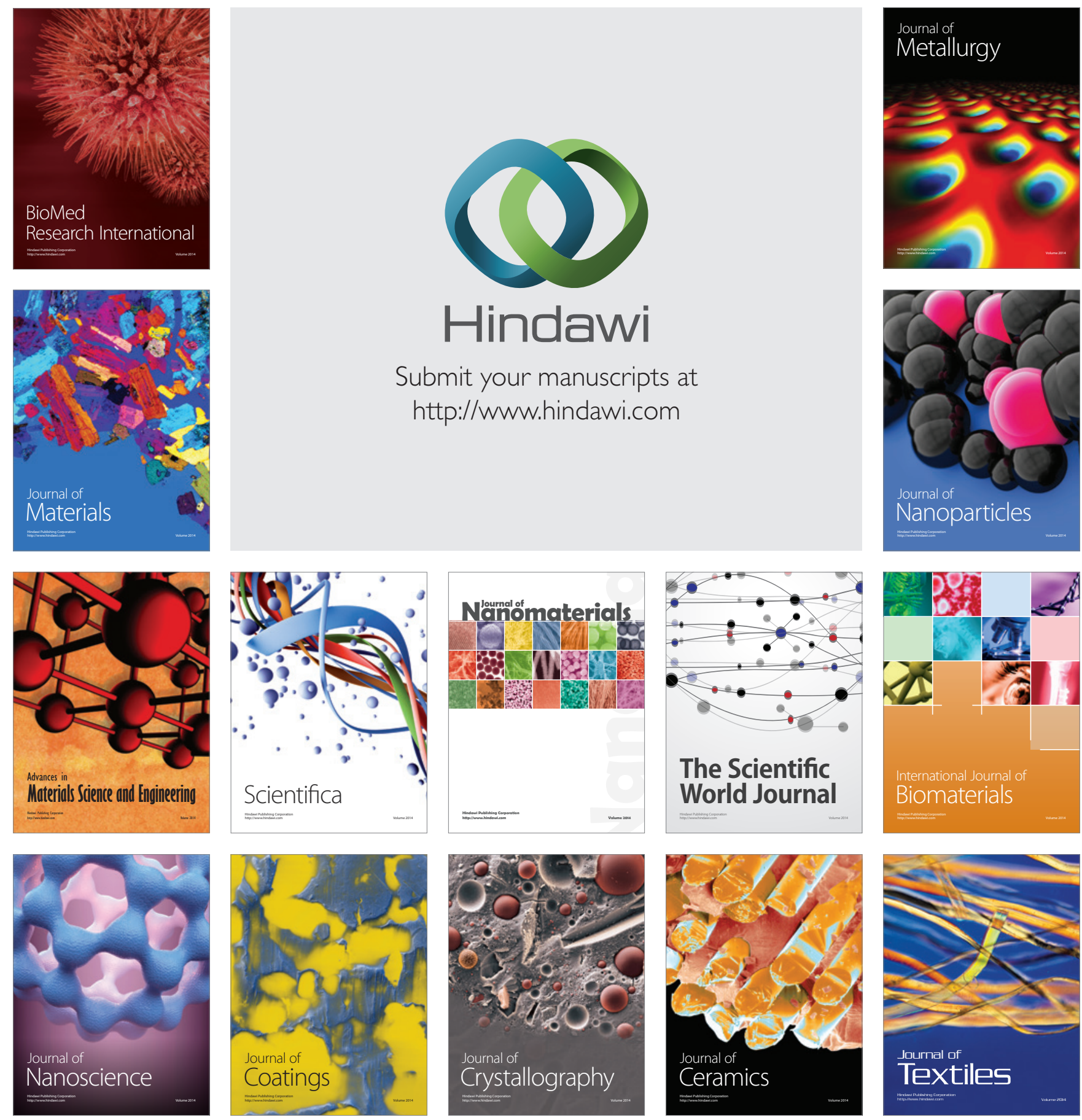